Review paper

\title{
The impact of technology on the changing practice of lung SBRT
}

\author{
Marianne Camille Aznar ${ }^{\mathrm{a}, \mathrm{b}, \mathrm{c}, *}$, Samantha Warren ${ }^{\mathrm{d}}$, Mischa Hoogeman ${ }^{\mathrm{e}}$, Mirjana Josipovic ${ }^{\mathrm{c}, \mathrm{f}}$ \\ ${ }^{a}$ Clinical Trial Service Unit, Nuffield Department of Population Health, University of Oxford, Oxford, UK \\ ${ }^{\mathrm{b}}$ Institute for Clinical Medicine, Faculty of Health Sciences, University of Copenhagen, Copenhagen, Denmark \\ ${ }^{\mathrm{c}}$ Niels Bohr Institute, Faculty of Science, University of Copenhagen, Copenhagen, Denmark \\ ${ }^{\mathrm{d}}$ Hall Edwards Radiotherapy Group, University Hospitals Birmingham NHS Foundation Trust, Birmingham, UK \\ e MC-Daniel den Hoed Cancer Center, Erasmus University, Rotterdam, Netherlands \\ ${ }^{\mathrm{f}}$ Department of Oncology, Section for Radiotherapy, Rigshospitalet, Copenhagen University Hospital, Copenhagen, Denmark
}

\section{A R T I C L E I N F O}

\section{Keywords:}

SBRT

SABR

Image guided radiotherapy

Hypofractionation

\begin{abstract}
A B S T R A C T
Stereotactic body radiotherapy (SBRT) for lung tumours has been gaining wide acceptance in lung cancer. Here, we review the technological evolution of SBRT delivery in lung cancer, from the first treatments using the stereotactic body frame in the 1990's to modern developments in image guidance and motion management. Finally, we discuss the impact of current technological approaches on the requirements for quality assurance as well as future technological developments.
\end{abstract}

\section{Introduction}

Radiotherapy has changed dramatically during the last decades, following advances in information technology and the wide progress in computer power and processing. Yet, there is a wide discrepancy in the distribution of technology not only between countries and institutions, but also among patient groups. Stereotactic body radiotherapy (SBRT) for lung tumours, also referred to as stereotactic ablative radiotherapy (SABR), is perhaps unique in the sense that it was originally targeted to patients with poor performance status (inoperable stage I lung cancer), but due to its success it is now gaining acceptance in operable patients. A large part of this success is attributable to technological advances in image guidance and motion management: increased precision in radiotherapy delivery enabled treatment of more challenging cases, which in turn meant that more patients became candidates for SBRT.

As the pool of patient candidates increases, the delivery of SBRT for lung cancer can no longer be limited to high-throughput academic centres. In this context, we observe the trend that SBRT is adopted by smaller and non-academic centres. We also observe that many technological solutions are available (see Table 1) and the investment in terms of equipment cost and human resources varies widely.

Lung SBRT is delivered in few fractions, typically 3-5. Hypofractionated treatment has benefits of preventing repopulation of neoplastic cells, a better cost effectiveness and is more convenient for patients compared to compared to conventional fractionation [1]. Bauman et al. [1] were the first to introduce the idea of cornerstones of SBRT in 2006; in a modern context these would be: 1) target localisation, 2) treatment planning and dose calculation, 3) hypofractionation and 4) motion management during treatment delivery. In this review, we aim to present the evolution of SBRT practice from the earliest clinical trials to today's practice. We will review the impact of the progressive technological advances on each cornerstone in terms of clinical workflow and patient outcome, where appropriate. In addition, we provide a discussion on patient selection and which technologies are, in today's perspective, considered a minimum standard ("must have") and which offer incremental improvements ("nice to have").

\section{Target localization}

Target localisation encompasses patient immobilisation, imaging for SBRT treatment planning, and in-room imaging for image guidance and verification. The choices made for each of these steps will have an impact on inter- and intra-fractional accuracy of dose delivery, and should be mirrored with appropriate treatment margins and a dose prescription level adapted to the target localisation method.

\subsection{Patient immobilisation}

Proper immobilisation permits reproducible positioning of the patient during the course of treatment, and is of crucial importance in highly precise treatments such as SBRT. Lax et al. developed a so-called stereotactic body frame enabling the first lung SBRT treatments [2]. This specially developed frame (see Fig. 1) served two purposes: it ensured the reproducible position of the patient through a head-to-

\footnotetext{
* Corresponding author at: Clinical Trial Service Unit, Nuffield Department of Population Health, University of Oxford, Richard Doll building, Roosevelt drive, OX3 7LF Oxford, UK.

E-mail address: marianne.aznar@ndph.ox.ac.uk (M.C. Aznar).
} 


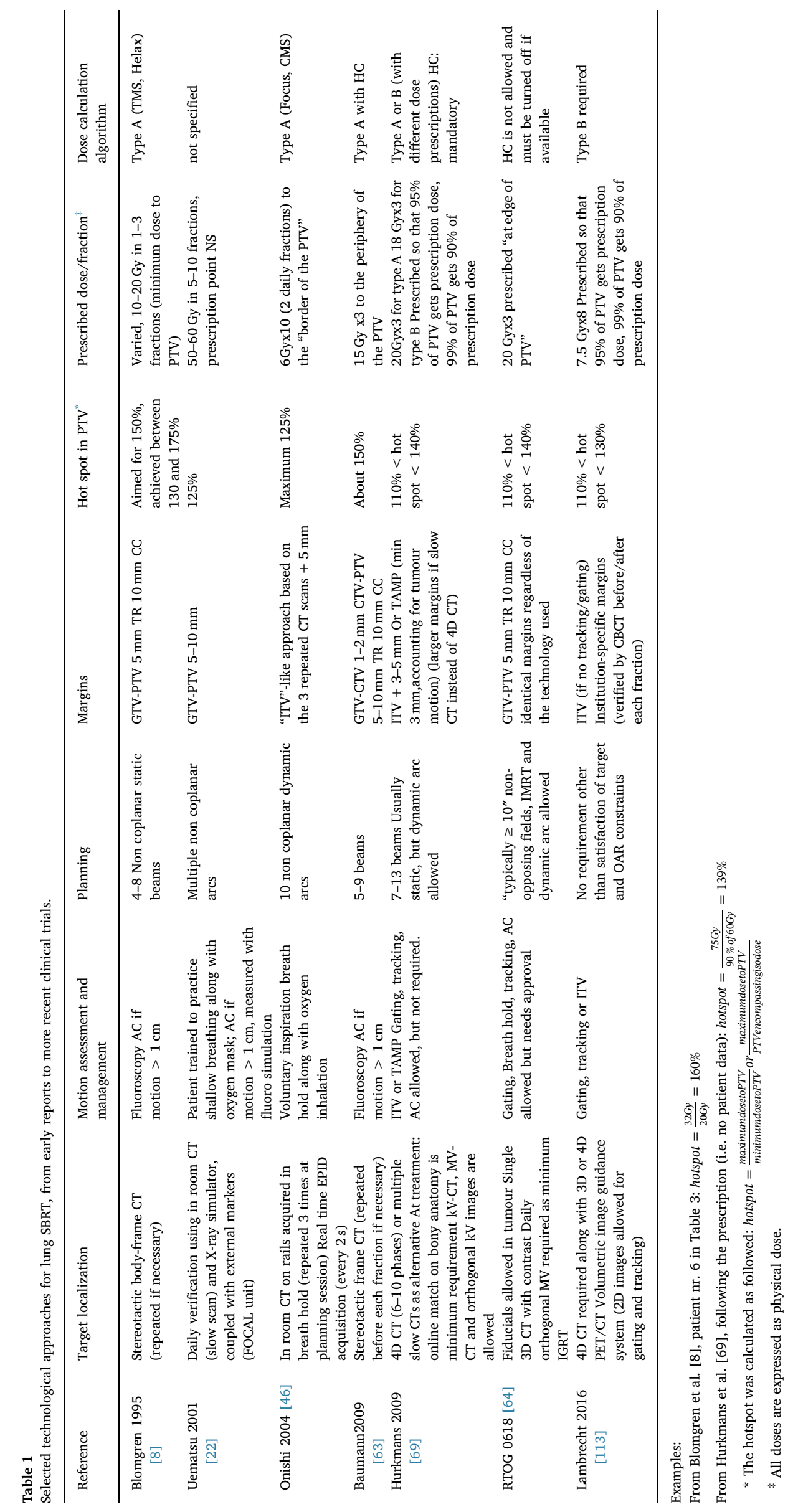




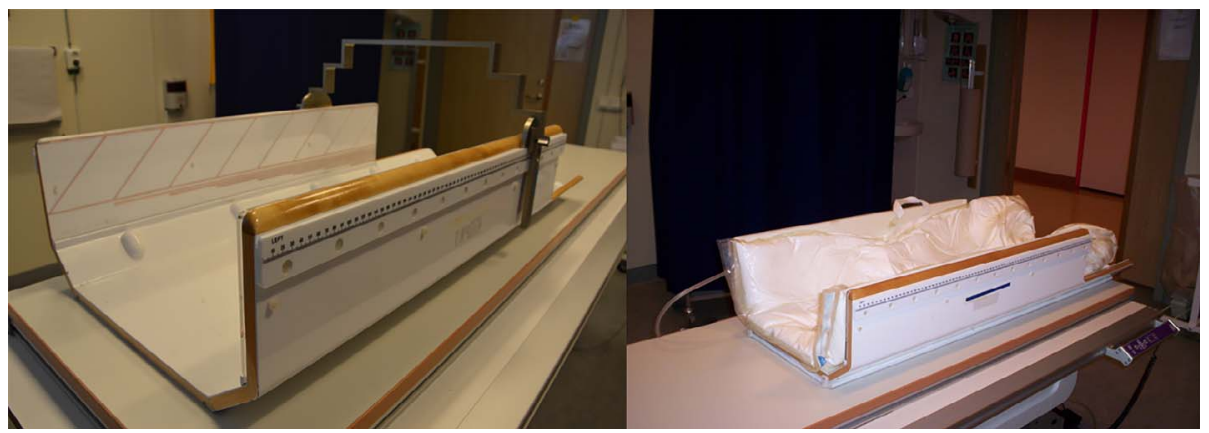

Fig. 1. The stereotactic body frame, as designed by the Karolinska institute. The coordinate system consists of a set of graduated scales, visible on CT images and is used to position the isocentre before each fraction. Abdominal compression was used if the motion of the diaphragm was estimated to be over $5 \mathrm{~mm}$ as assessed under quiet respiration fluoroscopy. Image courtesy of Kristin Karlsson, Karolinska institute. thighs vacuum pillow and provided an external coordinate system to localise the tumour inside the patient (similar to the head frames used in cranial treatment). In practice, it meant that target localisation for treatment was performed in two steps: first finding the CT-image coordinates of the tumour in the stereotactic frame and, second, aligning the isocentre of the linac with the treatment isocentre using these coordinates.

Today, several commercial versions of the stereotactic body frame are available [3], but with the advent of in-room imaging possibilities, the tumour can be visualised in one single step with the patient on the treatment couch. While some institutions retained the stereotactic frame for its immobilising properties combined with abdominal compression, others have phased it out and replaced it with devices with a lesser degree of immobilisation (such as chest boards or vacuum cushions). Frameless stereotactic treatments combined with daily image guidance $[4,5]$ showed residual uncertainties in tumour localisation similar to that of the stereotactic body frame $[6,7]$.

\subsection{Imaging for treatment planning}

SBRT also requires high quality imaging for treatment planning, with excellent visualisation of the tumour to enable precise target delineation. When the first patients receiving SBRT were treated at the Karolinska Institute in Stockholm, Sweden in 1994 [2], treatment planning based on computed tomography (CT) was used though it was not a standard procedure at the time. In addition, CT scans were acquired before each fraction in order to assess the reproducibility of the position of the tumours and baseline shifts $>5 \mathrm{~mm}$ in the CC direction were observed [8].

Awareness of interfraction tumour motion, combined with faster scan acquisition times, increased concerns about the reliability of conventional CT scans performed under quiet respiration: Shimizu et al. recommended the use of sequential CT scans for a more accurate estimate of the tumour localisation and appropriate treatment margins [9]. The use of slow CT scans was suggested as an alternative in the early 2000's: images are acquired with a gantry rotation of several seconds' duration, and the tumour is imaged throughout most of the breathing cycle, resulting in a larger (blurred) target volume and a more reproducible target visualisation than with a single conventional CT [10]. In addition, the range of tumour motion can be assessed using fluoroscopy, if the contrast between the tumour and surrounding tissue is sufficient or if fiducial markers are used (see "in-room image guidance" section below.

Respiratory correlated four dimensional CT (4DCT) was developed in the early 2000's [11], using externally measured respiratory signal coupled to an oversampled CT acquisition. Use of 4DCT for lung SBRT was first reported by Underberg et al. [12]: they found 4DCT advantageous over sequential 3D CTs for correct evaluation of the extent of individual tumour motion. Motion-related image artefacts were also reduced compared to regular 3D CT acquisitions [13,14]. However it should be remembered that the 4DCT remains just a snapshot of the tumour motion and position: the respiratory pattern may change with time [13] and in-room image guidance is required to verify the tumour position (and possibly, the position of the organs at risk) before each treatment fraction.

In order locate and delineate the tumour with high precision, high spatial resolution imaging is also necessary. The slice thickness of the CT images used for SBRT for the very first patients was $10 \mathrm{~mm}$ [2]. It has since been shown using phantom studies that the size of a small lesion is increasingly overestimated by large slice thickness [15], and for modern lung SBRT a slice thickness of $\leq 2 \mathrm{~mm}$ is desirable [16] (Table 2). Positron emission tomography (PET) for radiotherapy treatment planning is becoming increasingly available. Though it has been suggested that 4D PET/CT images (compared to 3D PET/CT) improve the inter-observer target delineation agreement for centrally located lesions [17], the primary role of PET imaging in lung SBRT remains to confirm the absence of disease spread, prior to referral [18]. Delineation uncertainties for the gross tumour volume (GTV) in lung SBRT of the order of $2 \mathrm{~mm}$ have been estimated by Persson et al. [19], when combining 3D PET/CT and 4DCT information. Although small, these uncertainties should still be included in the margins to be applied for treatment, to avoid geographical miss of part of the tumour.

Lung tumours can have a complex and irregular respiratory motion pattern. As a result, respiratory motion can degrade image quality in all imaging modalities, even respiratory-related ones. This needs to be evaluated and taken account for during imaging, or during registration of multiple images. Most tumours move predominantly in the craniocaudal direction [20] and have moderate peak-to-peak amplitude of $\leq 5 \mathrm{~mm}$ [21]. The degree and complexity of motion cannot be predicted from the anatomical tumour position, although in general, tumours in the lower lobes move more than those in the upper lobes of the lung.

\subsection{In-room image guidance and management of geometrical uncertainties in the position of the tumour}

In-room imaging for treatment guidance for lung SBRT was first reported using in-room CTs [22]. It became more widely available with the development of electronic portal imaging devices (EPID), enabling 2D MV imaging of either treatment fields beam's eye view or orthogonal setup images. However, MV image quality is poor, and visualisation of lung tumours is often not possible $[23,24]$. Planar $2 \mathrm{D} \mathrm{kV}$ imaging decreases imaging dose and improves image quality of the bony anatomy. In a selected group of patients (e.g., patients presenting with peripheral and well defined tumours), $2 \mathrm{D} \mathrm{kV}$ imaging can be used to directly visualize the tumour[25]. However, using bony anatomy as a surrogate for tumour position does not match the high precision requirements of modern lung SBRT and should be avoided [26,27] (see Table 2). 2D image registration based exclusively on bony anatomy is unfortunately still applied at a range of institutions, despite the well documented inter-fractional deviations between the bony anatomy and the SBRT lung target, ranging as high as $3 \mathrm{~cm}[6,28]$.

Visualising the tumour position is of paramount importance for daily verification in order to avoid geographical miss[3,29]. Percutaneously implanted fiducials can be used as an adequate surrogate for 
Table 2

Technological recommendations for lung SBRT anno 2017. These should be interpreted as general guidelines and not as strict requirements.

\begin{tabular}{|c|c|c|c|}
\hline & Routine and standard requirements & Advanced options & Comment \\
\hline \multirow[t]{3}{*}{ Treatment preparation } & CT slice thickness* $2 \mathrm{~mm}$ & CT slice thickness* $1 \mathrm{~mm}$ & $\begin{array}{l}\text { This requirement is stronger for smaller tumours } \\
(<1 \mathrm{~cm})\end{array}$ \\
\hline & 4DCT & 4D viewer for contouring & $\begin{array}{l}\text { Evaluation of tumour motion \& optimal baseline for } \\
\text { RT planning (via either midventilation or ITV } \\
\text { concept) }\end{array}$ \\
\hline & PET/CT For correct staging (for all patients) & $\begin{array}{l}\text { PET/CT co-registered with planning CT for } \\
\text { treatment planning }\end{array}$ & $\begin{array}{l}\text { Especially for the treatment planning of central lung } \\
\text { lesions }\end{array}$ \\
\hline \multirow[t]{9}{*}{$\begin{array}{l}\text { Treatment planning and } \\
\text { delivery }\end{array}$} & $\begin{array}{l}\text { Patient-specific/institution specific PTV } \\
\text { margin }\end{array}$ & & $\begin{array}{l}\text { The patient specific part is due to respiratory motion; } \\
\text { institution specific margins should include an } \\
\text { estimate of the geometrical uncertainties }\end{array}$ \\
\hline & $\begin{array}{l}\text { Dose calculation algorithm Type B (AAA, } \\
\text { Collapsed Cone or similar) }\end{array}$ & $\begin{array}{l}\text { Dose calculation algorithm Type C (MC, } \\
\text { Acuros), especially for very small targets }\end{array}$ & \\
\hline & Calculation grid size $2 \mathrm{~mm}$ & Calculation grid size $1 \mathrm{~mm}$ & Recommended by AAPM TG 101 [3] \\
\hline & Small field dosimetry & & Use of appropriate size dosimeter [3] \\
\hline & $\begin{array}{l}\text { Stereotactic linac/treatment machine } \\
\text { commissioned for field sizes }<3 \mathrm{~cm}\end{array}$ & & \\
\hline & $\begin{array}{l}\text { MLC leaf width } \leq 3 \mathrm{~mm} \text { for lesions }<3 \mathrm{~cm} \text {; } \\
\text { otherwise } \leq 5 \mathrm{~mm}\end{array}$ & MLC leaf width $\leq 3 \mathrm{~mm}$ & Recommended by AAPM TG 101 [3] \\
\hline & Beam energy 6-10 MV FF & $\begin{array}{l}\text { Beam energy } 6-10 \text { MV FFF to reduce } \\
\text { beam-on time (especially valuable if DIBH } \\
\text { is used) }\end{array}$ & \\
\hline & 3D conformal with at least 7 beam directions & $\begin{array}{l}\text { Non coplanar 3D CRT.VMAT/IMRT with } \\
\text { caution for interplay issues }\end{array}$ & \\
\hline & & $\begin{array}{l}\text { 4D CT contour propagation toolsDose } \\
\text { accumulation for } 4 \mathrm{D} \text { planning }\end{array}$ & \\
\hline \multirow[t]{3}{*}{$\begin{array}{l}\text { In room image guidance and } \\
\text { motion management }\end{array}$} & Daily & $\begin{array}{l}\text { Intra-fraction imaging (additional CBCT or } \\
\text { planar imaging with fiducial markers) }\end{array}$ & \\
\hline & $\begin{array}{l}\text { CBCT or Alternatively, } \mathrm{kV} \text { planar imaging } \\
\text { with fiducial marker inside the tumour (or } \\
\text { within } \sim 1 \mathrm{~cm} \text { ) }\end{array}$ & 4D CBCT for small very mobile tumours & \\
\hline & & $\begin{array}{l}\text { DIBH for very small tumours }(\varnothing<1 \mathrm{~cm}) \\
\text { with large motion }(>\sim 1 \mathrm{~cm}) \text {, especially if } \\
\text { no } 4 \text { D CBCT available } \\
\text { Respiratory gating or tracking for tumours } \\
\text { with large motion or near critical } \\
\text { structures }\end{array}$ & \\
\hline Quality assurance & $\begin{array}{l}\text { QA - end to end test } \\
\text { QA - patient specific pre-treatment } \\
\text { dosimetry for IMRT/VMAT } \\
\text { Special SBRT training for staff [3] }\end{array}$ & & \\
\hline
\end{tabular}

the position of the tumour, since it was shown that markers with nonsmooth surfaces are stable within the tumour throughout the treatment course [30-32]. However the implementation process comes with a high risk of pneumothorax [33-35]. This risk may be reduced by using endovascular coils [36] or bronchoscopy-guided implantation [37] but it remains present. In contrast, volumetric imaging is a non-invasive procedure where the tumours and the adjacent organs at risk can visualised. The use of in-room CT scanners on rails [28] and, more widely available, on-board $\mathrm{kV}$ cone beam CT (CBCT) resulted in improved geometrical precision of lung SBRT $[5,6,38,39]$ and reduced interfractional uncertainties.

Typical CBCT acquisition takes around one minute and hence consists of several breathing cycles, which may impact visibility and increase interobserver variation during registration. In the presence of substantial respiratory motion, time resolved 4D CBCT has been shown to improve image quality [40] and reduce the inter-observer variability associated with manual image registration [41]. In order to reduce the dose associated with 4D CBCT, O'Brien et al. have proposed reducing the number of projections acquired by using the breathing signal as an input [42]. At the time of writing, online pre-treatment 4D CBCT is not yet commercially available from all vendors of medical linear accelerators (linacs), but it is nonetheless gaining acceptance where available. The development and utilisation of 4D CBCT should be encouraged, especially in patients with small and very mobile tumours which can "disappear" on 3D CBCT image (Fig. 2a). Further work on the clinical implementation of $4 \mathrm{D}$ CBCT is required in order to make this form of in-room guidance available as a routine option for lung
SBRT patients. As an alternative, compliant patients with small mobile tumours can be imaged and treated in deep inspiration breath-hold (DIBH) (Fig. 2b).

Respiratory motion management strategies were used from the first implementations of lung SBRT. The most commonly reported strategy was abdominal compression $[8,22,43,44]$, but Japanese groups introduced breath hold, gating and even tracking in the early 2000s [45-48]. The efficiency of abdominal compression has been questioned: it may result in increased inter-fractional variation[49] and, while respiratory motion is decreased in some tumours, it is actually increased in others [50]. Strategies for gating and voluntary or controlled breath hold are covered in detail in Caillet et al. (this issue)[51] but it is important to remember that none of them completely eliminates breathing-related uncertainties. In addition, respiratory management strategies may only be applicable in patients who are relatively fit and compliant, either because they can create discomfort (active breathing control, abdominal compression), require active patient cooperation (voluntary breath hold) or increase the treatment delivery time (gating). Hence, appropriate patient selection is crucial for the implementation of those techniques which should be limited to compliant patients who get a substantial benefit in terms of improved accuracy.

In patients treated in free-breathing, remaining intra-fractional uncertainty of the tumour position, evaluated from a pre- and posttreatment $\mathrm{CBCT}$ would result in systematic and random errors within $\sim 2 \mathrm{~mm}[5,6,52]$. A mid-point (e.g. half way through a SBRT treatment) $\mathrm{CBCT}$ can be acquired to ensure minimal intra-fraction baseline shifts [53]. 

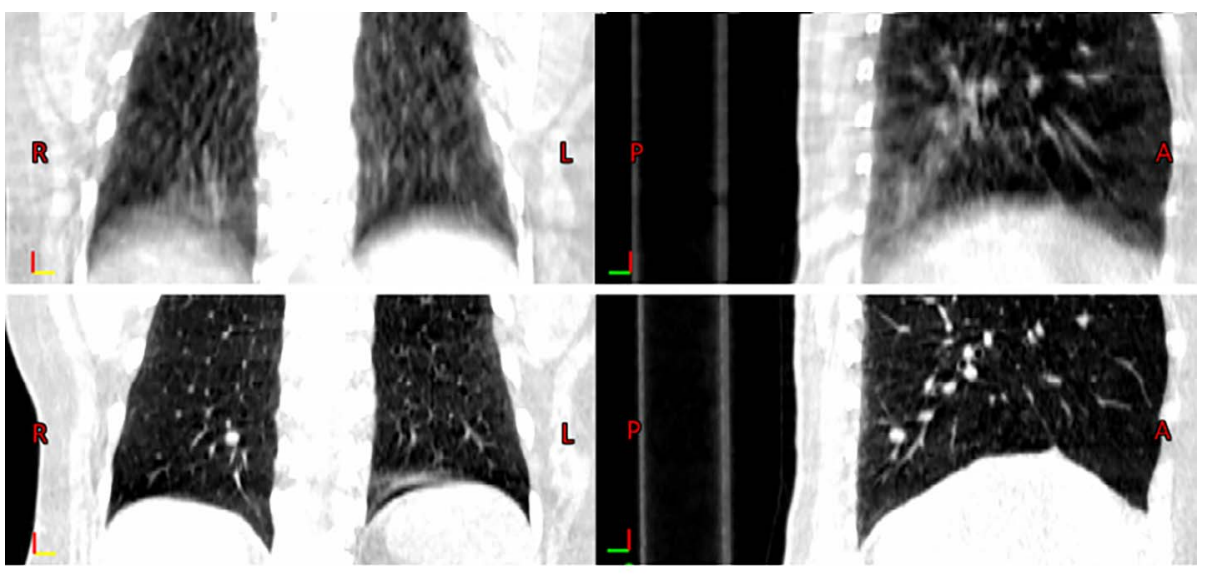

Fig. 2. a) top row: free breathing CBCT of a tumour with $9 \mathrm{~mm}$ diameter and respiratory motion of $15 \mathrm{~mm}$ in craniocaudal direction: the position of the tumour is not detectable. b) bottom row: CBCT acquired in deep inspiration breath hold (DIBH) resulted in clear representation of the target.
Surprisingly, intra-fractional uncertainties do not seem related to the degree of immobilisation [38] or extent of tumour motion [5] but it has been suggested that they are substantially increased with longer treatment duration (exceeding $34 \mathrm{~min}$ ) [6]. However, tracking the implanted fiducials during beam-on time revealed substantial intra-fractional base-line shifts occurring at an earlier time point [54]. Intrafraction monitoring is desirable and might reveal otherwise undetected shifts in some patients.

Acquisition of intra-fraction CBCT images for lung SBRT has also been described [55-58] by reconstructing CBCT images from planar $\mathrm{kV}$ images acquired during VMAT irradiation. This allows verification of the tumour position and movement during free-breathing, whilst the treatment beam is on, although there is a minimum treatment arc angular range of around $80^{\circ}$ required in order to generate useful СВСТ images. Current clinical implementation requires the $\mathrm{kV}$ fluoroscopy beam to be on during the entire treatment arc, so there may also be scope to reduce the imaging dose, e.g. by gating the $\mathrm{kV}$ fluoroscopy. These techniques are currently being introduced and commissioned by large academic centres, and some further development is required before they become widely available for routine implementation from all vendors.

\subsection{Treatment margins}

While GTV and clinical target volume (CTV) in lung SBRT are often considered to coincide [3], the planning target volume (PTV) should take into account all other uncertainties. The ITV concept, introduced in ICRU 62 was to account for internal organ motion separately from set-up or geometrical errors, which are then added to the PTV margins. However, it has been pointed out that the uncertainties should not be added linearly [59] and that use of ITV resulted in an "unnecessarily large volume" for random respiration variability. The ITV concept is still widely used in lung SBRT, but with slightly different approaches, resulting in a smaller treated volume: a simple fusion of GTV volumes delineated in inhale and exhale phases, delineating the GTV on the maximum intensity projection (MIP) images and fusion of GTVs from all respiratory phases of a 4DCT [60]. Another motion management approach is the use of midventilation or midposition [61,62], representing the time-averaged tumour position combined with a probability-based margin strategy.

Margins typically prescribed for SBRT were $10 \mathrm{~mm}$ in CC and $5 \mathrm{~mm}$ in AP and LR directions [3,63,64], based on tumour position deviations as measured in the first report on SBRT [2]. The reproducibility of target positioning was evaluated from several CT scans, which were coregistered according to the stereotactic body frame, and these margins corresponded roughly to the deviations seen between repeat CT scans. The first study using 4DCT for lung SBRT demonstrated that use of a standard PTV margin $(10 \mathrm{~mm})$ on 3D CT based treatment plan is not appropriate for two reasons: 1) for majority of patients the resulting PTVs will be larger compared to those established based on 4DCT 2) for highly mobile tumours these margins will not be sufficient and will result in risk of underdosing the tumour [12]. Therefore, instead of using standard margins, margins in lung SBRT should be based on the actual uncertainties measured and incorporated into a margin recipe (for instance [65]). These uncertainties include, but are not limited to, inter- and intra-fractional uncertainties of the tumour position (which depend on the type and frequency of IGRT together with observer uncertainties of the image registration process), delineation uncertainty, mechanical uncertainties of the linac (such as difference between the $\mathrm{kV}$ and MV isocentres and accuracy of treatment couch motion) and the size of beam penumbra, which is larger in low density lung tissue compared to soft tissue. Uncertainty of respiratory tumour motion is included in the ITV, but with the midventilation approach it should be added to the margin recipe. With midventilation-based margins, the resulting PTV may be smaller than with ITV-based margins $[4,66]$. Local control reported on almost 300 stage I NSCLC patients treated with SBRT using midventilation-based margins still showed $98 \%$ local control at 2 years [67]: in this study, no difference in local control or overall survival was observed between patients with very mobile tumours (amplitude $\geq 6.5 \mathrm{~mm}$ ) and patients with less mobile tumours.

\section{Dose planning and calculation}

\subsection{Dose prescription}

Inhomogeneous dose distributions were first rationalised for cranial stereotactic radiosurgery [68], where the hot spot in the centre of the tumour could be beneficial for eradicating an increased density of clonogenic tumour cells. The same argument was used upon implementation in extra cranial targets [1]. The resulting high dose fall off outside the PTV also limits the exposure of nearby organs at risk. However, there is no inter-institutional agreement or international code of practice for prescribing and reporting the dose to the target in lung SBRT. The most common practice is prescription to the isodose which encompasses the PTV (see examples in Table 1). In RTOG 0236, 0618 and 0915 lung SBRT trials the prescription dose was three fractions of $20 \mathrm{~Gy}$, prescribed to the isodose covering the PTV, which can be between $60 \%$ and $90 \%[69,70]$. As the maximum dose was $100 \%$, this produced very different degree of heterogeneity within the target. In the Scandinavian tradition, $45 \mathrm{~Gy}$ in three fractions is prescribed to the PTV encompassing 65\% isodose [71]. This can be presented equivalently, as the $100 \%$ isodose encompassing the PTV with a $140 \%-150 \%$ hot spot at the isocenter [1]. Within the ROSEL trial, the RTOG 0618 dose prescription was specified in a similar way, with $95 \%$ of the PTV receiving nominal fraction dose of $20 \mathrm{~Gy}$, and aiming for a maximum dose of $110-140 \%$ [69]. A discussion of how to achieve these 
inhomogeneous dose distributions is presented by Giglioli et al. in this issue [72].

Studies have also been published with different dose prescription approaches: to mean PTV dose, maximum dose and even with relatively homogeneous dose distribution within the target [73,74]. As discussed by Ricardi et al. in this issue [75], this is still considerable debate about the optimal dose prescription and fractionation in lung SBRT. The variety of dose prescription practices (see table 1 and the calculation example provided) makes it challenging to compare studies from a dosimetric point of view and the introduction of standard methods of dose reporting are sorely needed.

\subsection{Dose calculation algorithms}

The accuracy of the calculated dose distribution in lung SBRT is affected by uncertainties related to small-field dosimetry (which will impact input data used in dose calculation algorithms), and handling the lateral electron transport and charged particle disequilibrium. Knöös et al. divided dose calculation algorithms used in commercially available treatment planning systems into simple ones not taking into account changes in electron transport (type A), and more complex ones (type B), which partially account for these changes in electron transport [76]. Both type A and B algorithms are analytical or semi-analytical. The third-generation algorithms, recently referred to as type $\mathrm{C}$, solve the linear Boltzmann transport equations either stochastically (Monte Carlo) or deterministically (Acuros XB). Modelling physical interactions of particles in media enables reporting absorbed dose as dose-to-media as opposed to widely used dose-to-water. There have been some controversies as to which to use [77], and AAPM TG 105 recommended indicating the material to which the dose was computed, and allowing conversion from dose-to-medium to dose-to-water, until clinical justification for either method was assessed [78]. The properties and dosimetric impact of these different algorithms are reviewed in detail in other articles within the present issue $[66,79]$.The choice of dose calculation algorithm in lung SBRT has been shown to have a significant impact on treatment outcomes. Recurrence rates for type A algorithm planned SBRT were higher (hazard ration 3.4; 95\% CI: 1.18-0.83) [80], despite tumours treated in the type A group were smaller [80]. 2 years local control was in better agreement with dose recalculated with type B or C algorithms [81].

Recent SBRT trials require use of type B or C algorithms (RTOG 0915) or suggest differentiating the prescribed dose according to the dose calculation algorithm of choice $[69,82]$.

The accuracy of the calculated dose distribution is also affected by the calculation grid size. AAPM TG 101 recommends using $2 \mathrm{~mm}$ or smaller grid size [3], although a $1 \mathrm{~mm}$ calculation grid size for Acuros $\mathrm{XB}$ has not shown statistically significant benefits for lung SBRT delivered with VMAT [83]. Optimisation of Monte Carlo approaches is discussed by Chetty et al., however without focus on SBRT [78].

\subsection{Dose prediction and verification prior to delivery}

Recent developments in handling 4D-CT image datasets in commercial treatment planning systems (TPS) have opened up the possibility of in silico assessment of treatment plans across all breathing phases. These capabilities have so far been used more in the research setting than in clinical routine [84] and rely heavily on the use of deformable image registration (DIR). The accuracy of DIR algorithms in commercial TPS is probably sufficient in the high-contrast thoracic region to be useful for propagation of the outline of normal tissues. A 3-5 mm variation in contour accuracy between different commercial software packages has been found [85], and variations of the same magnitude are also found when using the same software package, but different workflow. This highlights that work still remains to be done on establishing guidelines for use of DIR software, along with an evaluation of the size of registration errors for specific tumour sites [86].
The development of semi-automated tools (which allow re-calculation of the treatment plan dose on each phase of the 4D CT) now permit inspection of the dose distribution(s) throughout the breathing cycle prior to treatment. Plan assessment tools such as DVH graphs with error limits or confidence intervals to guide the user in assessing multiple plans would be helpful in future software development.

Use of DIR for dose warping or dose accumulation (to sum the dose delivered across all breathing phases onto a single reference phase) is more problematic. Errors in the deformation vector, particularly in zones with a high dose gradient could lead to very significant errors in accumulated dose $[87,88]$. Further work is also necessary to fully examine the interplay effect - this requires information about the duration of the breathing cycle, and timing of the treatment delivery, particularly for intensity-modulated beams. Inverse optimisation of plans using multiple phases of the 4D CT image dataset could also be implemented in the future, to create treatment plans which are 'robust' to breathing motion. Experimental evaluation of the accuracy of 3D versus 4D planning suggests that for each patient, uncertainties in 4D planning need to be smaller than the uncertainties in the standard 3D approach, in order for this technique to be adopted in clinical routine [89].

\section{New delivery techniques in lung SBRT}

The development of volumetric modulated arc therapy (VMAT), in particular when coupled with the introduction of flattening filter free (FFF) beams with dose rates of $2400 \mathrm{MU}$ per minute, has allowed lung SBRT plans to be delivered much more rapidly and conveniently than multiple static beams. Delivery of lung SBRT plans using FFF arc therapy has been shown to be feasible with acceptable acute toxicity rates [90].

Some caution is required when selecting patients for these treatments, to avoid any kind of interplay effect, where the periodic nature of tumour displacement, and the temporal pattern of dose delivery could overlap to degrade the delivered dose compared to that planned on the 'static' CT image used for planning. Experimental phantom studies have suggested that the interplay effect is significant for large tumour displacements $(>3 \mathrm{~cm})$ or very long respiratory patterns (period > 60s) [91].

Specialised treatment machines, such as the Cyberknife robotic radiosurgery system, allow tracking of the tumour in real-time, by constructing a patient specific correlation model to monitor the respiratory tumour movement, and reposition the treatment beam using the robotic treatment arm. Briefly: external optical markers (endpoints of optical fibres that transport the light of light-emitting diodes) are placed on the chest or abdomen of the patient and are monitored by a camera array and correlated with the tumour location derived from orthogonal $\mathrm{kV} \mathrm{X}$-ray images of the patient anatomy. The correlation model is constructed prior to each treatment fraction and verified and adapted during each treatment fraction. Fiducials can be used for target localisation, and Cyberknife treatment using fiducial tracking has been found to give comparable results for 3 year local control (91\%) as for surgical resection [92]. A fiducial-less tracking system (Xsight lung tracking) is also available, and measurements on patient specific lung phantoms indicate this tracking accuracy (with mean error $0.38 \pm 0.54 \mathrm{~mm}$ craniocaudal) is comparable to tracking using fiducials [93]. However, not all lung tumours may be amenable to tracking using the fiducial-less system - small tumours with low density being more challenging to visualize during treatment [25]. If implanted fiducials are not available and the tumour cannot be localized directly by one of the two X-ray cameras, there is an option to use only one X-ray camera for real-time tracking. A treatment margin is then needed to encompass the motion that is blinded to the other X-ray camera and is therefore not being tracked. If implanted fiducials are not available and the tumour cannot be localized by either X-ray camera, margins need to be added that account for the full inhale-to-exhale motion of the tumour. 
Efforts are also made to increase the potential of DIBH treatments: Péguret et al. have reported achieving apnea-like conditions lasting up to 16.5 min using a pneumatic ventilation system [94]. Though compliance was acceptable in the healthy volunteers, one out of five patients could not hold a long enough breath hold to be treated with this approach and further investigation is necessary to judge whether this approach is feasible in clinical practice.

\section{Quality assurance}

Geometric tests for verification of the alignment and coincidence of the mechanical and radiation isocentres and the image guidance system should be tighter for machines delivering SBRT treatments: for example, a maximum difference of $\pm 1 \mathrm{~mm}$ compared to the indicated position, and $\pm 0.5^{\circ}$ in rotation (as opposed to $\pm 2 \mathrm{~mm} / 1^{\circ}$ for conventional RT) has been recommended [3,95]. QA procedures have to be performed frequently and should include a daily check of the coincidence of treatment (MV) and imaging (kV) isocentres [27,29]. For volumetric vs planar $\mathrm{kV}$ in-room imaging, reported isocentre deviations were within $1 \mathrm{~mm}$ [96].

Although checking each component individually is required, end-toend (E2E) testing using simple geometric phantoms $[97,98]$ is also recommended, and developments in EPID technology mean these tests can be now be semi- or fully automated [99].

For lung SBRT, a patient specific QA program using E2E tests with a heterogeneous anthropomorphic phantom [100] is required, as this can be used to verify the mechanical, dosimetric and imaging components for SBRT delivery, and also check correct transfer and application of image-guidance positioning data (see an example in Fig. 3). Additional QA may be required when using a robotic " 6 degrees of freedom" couch, to correct for rotational errors in patient position [101]. Hurkmans et al. [102] showed that differences in 4D-CT protocols (due to, e.g. type of scanner, breathing surrogate or image reconstruction strategy) could introduce systematic errors in the treatment planning process: regular QA checks using a moving phantom can help optimise 4D acquisition protocols and should be included in the commissioning program. Consideration should be given to the quality of images to be used during real-time imaging for each patient, as image contrast or target visibility may be degraded compared to studies using phantoms due to patient size or other artefacts. This is especially important if tracking or gating is applied, and specific QA procedures relevant to the exact configuration of each treatment and imaging system will be necessary [103].

The challenges associated with small field dosimetry have been described [27], and use of a detector with an active area of $1 \mathrm{~mm}^{2}$ or less is recommended for SBRT dose measurements [3]. A new formalism for small-field reference dosimetry has been proposed, which is also applicable to treatment machines such as CyberKnife or Tomotherapy where the reference geometry outlined in the standard code of practice is not achievable [104]. In addition, the development of flattening-filter free (FFF) linacs (e.g. Varian Truebeam and Elekta Agility HD) which do not deliver 'flat' beam profiles also means that standard parameters for field homogeneity and flatness are no longer applicable. Novel parameters for beam profile consistency checks have recently been proposed and analysed $[105,106]$.

Frequent use of non-co-planar fields means that in addition to collision verification, the dosimetric effects of the treatment couch and immobilisation devices on beam attenuation or increased skin dose should be considered in the delivery of high-dose per fraction treatments with standard or FFF beams $[107,108]$.

A list of guidelines and protocols specific to SBRT is given in the Supplementary Table material. These also give guidelines on staffing and resources needed to implement a successful SBRT program. Reports for commissioning and benchmarking QA procedures for specialised machines such as CyberKnife [103], Novalis [109], Vero [110] are also available. In addition, a review of in vivo dosimetry methods is given by McCurdy et al. [111] (this issue).

\section{Discussion \& conclusion}

SBRT has led the development of technologies that are today widely used for other treatment schemes and diagnostic sites. The improvements in local control and overall survival in patients treated with SBRT cannot be ascribed to technology alone, but it has certainly played a role: improved SBRT technology facilitated safely escalating the dose to the tumour, which in turn seems to correlate with improved outcomes [112]. The potential of future technological developments may be classified in three categories: 1) workflow improvements (such as FFF or automated planning and contouring), 2) improvements likely to show a clinical benefit in a small number of patients, and 3) improvements likely to benefit the group of SBRT patients as a whole. Innovations in intra fraction management arguably belong to the second category and will be welcome for a subgroup of patients with very mobile tumours. Improved imaging for contouring of tumours and organs at risk is also desirable especially in central lung tumours [113], but we are presently missing data about which structures drive toxicity and how much they should be spared. When this knowledge becomes available, advanced delivery techniques (such as proton therapy or MRI-guided RT (Menten et al. [114] this issue)) may prove valuable for a larger group of patients.

The next technological priority belonging to the third category and benefitting the largest group of patients should be on standardisation (for example, in reporting heterogeneous dose distributions) and/or a better use of the technology available today. This means more thorough commissioning and rigorous QA so that the present technology can be used close to its potential accuracy. It is worth noting that even in these optimal conditions, uncertainties will be present and zero-margins are unlikely to be achieved.

Optimal use of the technology currently available will both benefit clinical practice and ensure the highest quality in clinical trials.

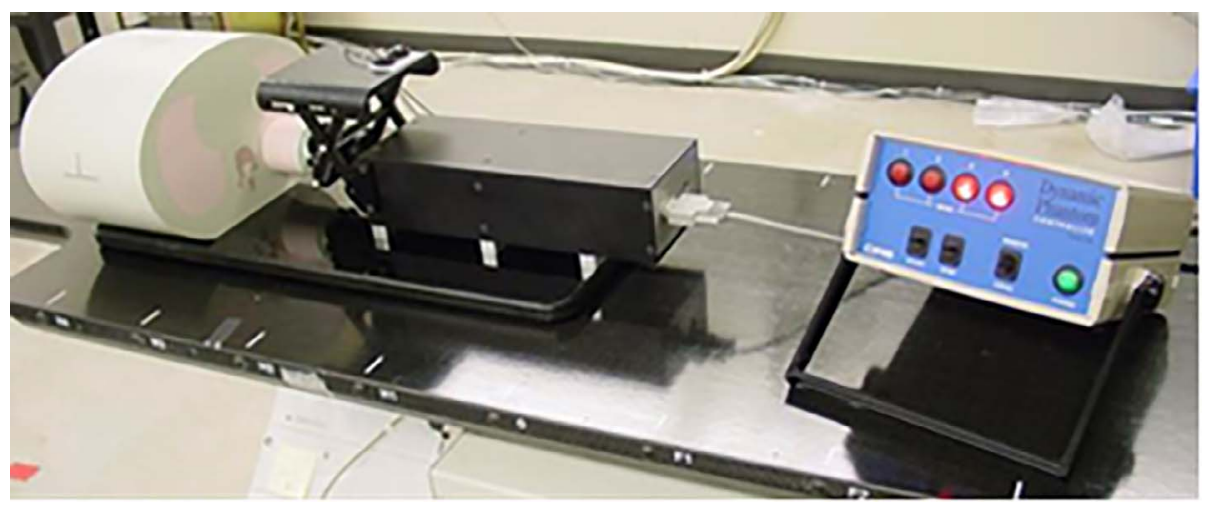

Fig. 3. Motion phantom used for end-to-end testing of tracking at Erasmus MC. 
Unfortunately, this is not yet the case and a few current trials still allow the use of 2D portal imaging for peripheral lung tumours despite the wide availability of CBCT (or other methods which enable to visualize the position of the tumour) and the well-documented uncertainty of portal imaging.

Along with developing new tools and making the most of the ones we already have, the ultimate goal is to achieve high quality and high precision lung SBRT in both clinical trials and "daily" treatments, in both academic and non-academic institutions, benefiting all SBRT patients.

\section{Acknowledgements}

MCA acknowledges the financial support of Cancer Research UK (grant no C8225/A21133).

\section{Appendix A. Supplementary data}

Supplementary data associated with this article can be found, in the online version, at http://dx.doi.org/10.1016/j.ejmp.2017.12.020.

\section{References}

[1] Baumann P, Nyman J, Lax I, Friesland S, Hoyer M, Rehn Ericsson S, et al. Factors important for efficacy of stereotactic body radiotherapy of medically inoperable stage I lung cancer. A retrospective analysis of patients treated in the Nordic countries. Acta Oncol 2006;45:787-95. http://dx.doi.org/10.1080/ 02841860600904862

[2] Lax I, Blomgren H, Näslund I, Svanström R. Stereotactic radiotherapy of malignancies in the abdomen. Methodological aspects. Acta Oncol 1994;33:677-83. http://dx.doi.org/10.3109/02841869409121782.

[3] Benedict SH, Yenice KM, Followill D, Galvin JM, Hinson W, Kavanagh B, et al. Stereotactic body radiation therapy: the report of AAPM Task Group 101. Med Phys 2010;37:4078. http://dx.doi.org/10.1118/1.3438081.

[4] Sonke J-J, Rossi M, Wolthaus J, van Herk M, Damen E, Belderbos J. Frameless stereotactic body radiotherapy for lung cancer using four-dimensional cone beam ct guidance. Int J Radiat Oncol 2009;74:567-74. http://dx.doi.org/10.1016/j. ijrobp.2008.08.004.

[5] Josipovic M, Persson GF, Logadottir A, Smulders B, Westmann G, Bangsgaard JP. Translational and rotational intra- and inter-fractional errors in patient and target position during a short course of frameless stereotactic body radiotherapy. Acta Oncol (Madr) 2012;51:610-7. http://dx.doi.org/10.3109/0284186X.2011. 626448.

[6] Purdie TG, Bissonnette JP, Franks K, Bezjak A, Payne D, Sie F, et al. Cone-beam computed tomography for on-line image guidance of lung stereotactic radiotherapy: localization, verification, and intrafraction tumor position. Int $\mathrm{J}$ Radiat Oncol Biol Phys 2007;68:243-52. http://dx.doi.org/10.1016/j.ijrobp.2006.12. 022.

[7] Garibaldi C, Piperno G, Ferrari A, Surgo A, Muto M, Ronchi S, et al. Translational and rotational localization errors in cone-beam CT based image-guided lung stereotactic radiotherapy. Phys Medica 2016;32:859-65. http://dx.doi.org/10.1016/ j.ejmp.2016.05.055.

[8] Blomgren H, Lax I, Näslund I, Svanström R. Stereotactic high dose fraction radiation therapy of extracranial tumors using an accelerator. Clinical experience of the first thirty-one patients. Acta Oncol 1995;34:861-70. http://dx.doi.org/10. 3109/02841869509127197.

[9] Shimizu S, Shirato S, Kagei K, Nishioka T, Bo X, Dosaka-Akita H, et al. Impact of respiratory movement on the computed tomographic images of small lung tumors in three-dimensional (3D) radiotherapy. Int J Radiat Oncol Biol Phys 2000;46:1127-33.

[10] Lagerwaard FJ, Sornsen Van, de Koste JR, Nijssen-Visser MRJ, SchuchhardSchipper RH, Oei SS, et al. Multiple "slow" CT scans for incorporating lung tumor mobility in radiotherapy planning. Int J Radiat Oncol Biol Phys 2001;51:932-7. http://dx.doi.org/10.1016/S0360-3016(01)01716-3.

[11] Kini V, Vedam S, Keall P, Patil S, Chen C, Mohan R. Patient training in respiratorygated radiotherapy. Med Dosim 2003;28:7-11.

[12] Underberg RWM, Lagerwaard FJ, Cuijpers JP, Slotman BJ, Koste Van Sörnsen De, Senan JR S. Four-dimensional CT scans for treatment planning in stereotactic radiotherapy for stage I lung cancer. Int J Radiat Oncol Biol Phys 2004;60:1283-90. http://dx.doi.org/10.1016/j.ijrobp.2004.07.665.

[13] Keall PJ, Mageras GS, Balter JM, Emery RS, Forster KM, Jiang SB, et al. The management of respiratory motion in radiation oncology report of AAPM Task Group 76. Med Phys 2006;33:3874. http://dx.doi.org/10.1118/1.2349696.

[14] Vedam S, Keall P, Kini VR, Mostafavi H, Shukla HP, Mohan R. Acquiring a four dimensional computed tomography dataset using an external respiratory signal. Phys Med Biol 2003;48:45-62.

[15] Winer-muram HT, Jennings SG, Meyer CA, Liang Y, Aisen AM, Tarver RD, et al. Effect of varying CT section width on volumetric measurement of lung tumors and application of compensatory equations. Radiology 2003;229:184-94.
[16] Foote M, Bailey M, Smith L, Siva S, Hegi-Johnson F, Seeley A, et al. Guidelines for safe practice of stereotactic body (ablative) radiation therapy. J Med Imaging Radiat Oncol 2015;59:646-53. http://dx.doi.org/10.1111/1754-9485.12336.

[17] Chirindel A, Adebahr S, Schuster D, Schimek-Jasch T, Schanne DH, Nemer U, et al Impact of 4D-18FDG-PET/CT imaging on target volume delineation in SBRT patients with central versus peripheral lung tumors. Multi-reader comparative study. Radiother Oncol 2015;115:335-41. http://dx.doi.org/10.1016/j.radonc.2015.05. 019.

[18] Usmanij EA, de Geus-Oei L-F, Bussink J, Oyen WJG. Update on F-18-fluoro-deoxyglucose-PET/computed tomography in nonsmall cell lung cancer. Curr Opin Pulm Med 2015;21:314-21. http://dx.doi.org/10.1097/MCP.0000000000000182.

[19] Persson GF, Nygaard DE, Hollensen C, Af Rosenschold PM, Mouritsen LS, Due AK, et al. Interobserver delineation variation in lung tumour stereotactic body radiotherapy. Br J Radiol 2012;85:e654-60. http://dx.doi.org/10.1259/bjr/76424694.

[20] Seppenwoolde Y, Shirato H, Kitamura K, Shimizu S, van Herk M, Lebesque J, et al. Precise and real-time measurement of 3D tumor motion in lung due to breathing and heartbeat, measured during radiotherapy. Int J Radiat Oncol Biol Phys 2002;53:822-34

[21] Korreman S, Persson G, Nygaard D, Brink C, Juhler-Nøttrup T. Respiration-correlated image guidance is the most important radiotherapy motion management strategy for most lung cancer patients. Int $\mathrm{J}$ Radiat Oncol Biol Phys 2012;83:1338-43. http://dx.doi.org/10.1016/j.ijrobp.2011.09.010.

[22] Uematsu M, Shioda A, Suda A, Fukui T, Ozeki Y, Hama Y, et al. Computed tomography-guided frameless stereotactic radiotherapy for stage I non-small cell lung cancer: a 5-year experience. Int J Radiat Oncol Biol Phys 2001;51:666-70. http://dx.doi.org/10.1016/S0360-3016(01)01703-5.

[23] Esposito M, Maggi G, Marino C, Bottalico L, Cagni E, Carbonini C, et al. Multicentre treatment planning inter-comparison in a national context: the liver stereotactic ablative radiotherapy case. Phys Medica 2016;32:277-83. http://dx. doi.org/10.1016/j.ejmp.2015.09.009.

[24] Richter A, Wilbert J, Baier K, Flentje M, Guckenberger M. Feasibility study for markerless tracking of lung tumors in stereotactic body radiotherapy. Int $\mathrm{J}$ Radiat Oncol Biol Phys 2010;78:618-27. http://dx.doi.org/10.1016/j.ijrobp.2009.11. 028.

[25] Bahig H, Campeau MP, Vu T, Doucet R, Béliveau Nadeau D, Fortin B, et al. Predictive parameters of cyberknife fiducial-less (XSight Lung) applicability for treatment of early non-small cell lung cancer: a single-center experience. Int $\mathrm{J}$ Radiat Oncol Biol Phys 2013;87:583-9. http://dx.doi.org/10.1016/j.ijrobp.2013. 06.2048 .

[26] Sahgal A, Roberge D, Schellenberg D, Purdie TG, Swaminath A, Pantarotto J, et al. The Canadian Association of Radiation Oncology scope of practice guidelines for lung, liver and spine stereotactic body radiotherapy. Clin Oncol (R Coll Radiol) 2012;24:629-39. http://dx.doi.org/10.1016/j.clon.2012.04.006.

[27] Solberg TD, Balter JM, Benedict SH, Fraass BA, Kavanagh B, Miyamoto C, et al Quality and safety considerations in stereotactic radiosurgery and stereotactic body radiation therapy: Executive summary. Pract Radiat Oncol 2012;2:2-9. http://dx.doi.org/10.1016/j.prro.2011.06.014.

[28] Ikushima H, Balter P, Komaki R, Hunjun S, Bucci MK, Liao Z, et al. Daily alignment results of in-room computed tomography-guided stereotactic body radiation therapy for lung cancer. Int J Radiat Oncol Biol Phys 2011;79:473-80. http://dx. doi.org/10.1016/j.ijrobp.2009.11.009.

[29] Bissonnette J-P, Balter P, Dong L, Langen KM, Lovelock DM, Miften M, et al. Quality assurance for image-guided radiation therapy utilizing CT-based technologies: a report of the AAPM TG-179. Med Phys 2012;39:1946-63. http://dx.doi. org/10.1118/1.3690466.

[30] Van Der Voort Van Zyp NC, Hoogeman MS, Van De Water S, Levendag PC, Van Der Holt B, Heijmen BJM, et al. Stability of markers used for real-time tumor tracking after percutaneous intrapulmonary placement. Int J Radiat Oncol Biol Phys 2011;81:75-81. http://dx.doi.org/10.1016/j.ijrobp.2010.12.026.

[31] Hong JC, Yu Y, Rao AK, Dieterich S, Maxim PG, Le QT, et al. High retention and safety of percutaneously implanted endovascular embolization coils as fiducial markers for image-guided stereotactic ablative radiotherapy of pulmonary tumors. Int J Radiat Oncol Biol Phys 2011;81:85-90. http://dx.doi.org/10.1016/j.ijrobp. 2010.04.037.

[32] Persson GF, Josipovic M, Von Der Recke P, Aznar MC, Juhler-Nøttrup T, Rosenschöld PMA, et al. Stability of percutaneously implanted markers for lung stereotactic radiotherapy. J Appl Clin Med Phys 2013;14:187-95. http://dx.doi. org/10.1120/jacmp.v14i5.4337.

[33] Persson GF, Josipovic M, Nygaard DE, Von Der Recke P, Aznar M, Juhler-nøttrup T, et al. Percutaneously implanted markers in peripheral lung tumours: report of complications. Acta Oncol (Madr) 2013;52:2-7. http://dx.doi.org/10.3109/ 0284186X.2013.764009.

[34] Kothary N, Heit JJ, Louie JD, Kuo WT, Loo BW, Koong A, et al. Safety and efficacy of percutaneous fiducial marker implantation for image-guided radiation therapy. J Vasc Interv Radiol 2009;20:235-9. http://dx.doi.org/10.1016/j.jvir.2008.09. 026.

[35] Yousefi S, Collins BT, Reichner CA, Anderson ED, Jamis-Dow C, Gagnon G, et al. Complications of Thoracic Computed Tomography-Guided Fiducial Placement for the Purpose of Stereotactic Body Radiation Therapy. Clin Lung Cancer 2007;8:252-6. http://dx.doi.org/10.3816/CLC.2007.n.002.

[36] Prévost JBG, Nuyttens JJ, Hoogeman MS, Péll JJ, Dijk LC, Pattynama PMT. Endovascular coils as lung tumour markers in real-time tumour tracking stereotactic radiotherapy: preliminary results. Eur Radiol 2008;18:1569-76. http://dx. doi.org/10.1007/s00330-008-0933-x.

[37] Nabavizadeh N, Zhang J, Elliott DA, Tanyi JA, Thomas CR, Fuss M, et al. Electromagnetic navigational bronchoscopy-guided fiducial markers for lung 
stereotactic body radiation. Therapy 2014;21:123-30.

[38] Grills IS, Hugo G, Kestin LL, Galerani AP, Chao KK, Wloch J, et al. Image-guided radiotherapy via daily online cone-beam CT substantially reduces margin requirements for stereotactic lung radiotherapy. Int $\mathrm{J}$ Radiat Oncol Biol Phys 2008;70:1045-56. http://dx.doi.org/10.1016/j.ijrobp.2007.07.2352.

[39] Borst GR, Sonke J-J, Betgen A, Remeijer P, van Herk M, Lebesque JV. Kilo-voltage cone-beam computed tomography setup measurements for lung cancer patients; first clinical results and comparison with electronic portal-imaging device. Int $\mathrm{J}$ Radiat Oncol 2007;68:555-61. http://dx.doi.org/10.1016/j.ijrobp.2007.01.014.

[40] Sonke J-J, Zijp L, Remeijer P, van Herk M. Respiratory correlated cone beam CT. Med Phys 2005;32:1176-86. http://dx.doi.org/10.1118/1.1869074.

[41] Sweeney R, Seubert B, Stark S, Homann V, Müller G, Flentje M, et al. Accuracy and inter-observer variability of 3D versus 4D cone-beam CT based image-guidance in SBRT for lung tumors. Radiat Oncol 2012;7:81. http://dx.doi.org/10.1186/1748717X-7-81.

[42] O'Brien RT, Cooper BJ, Shieh C-C, Stankovic U, Keall PJ, Sonke J-J. The first implementation of respiratory triggered 4DCBCT on a linear accelerator. Phys Med Biol 2016;61:3488-99. http://dx.doi.org/10.1088/0031-9155/61/9/3488.

[43] Takeda A, Kunieda E, Shigematsu N, Hossain DM, Kawase T, Ohashi T, et al. Small lung tumors: long-scan-time CT for planning of hypofractionated stereotactic radiation therapy-initial findings. Radiology 2005;237:295-300. http://dx.doi.org/ 10.1148/radiol.2371032102.

[44] Nagata Y, Takayama K, Matsuo Y, Norihisa Y, Mizowaki T, Sakamoto T, et al. Clinical outcomes of a phase I/II study of $48 \mathrm{~Gy}$ of stereotactic body radiotherapy in 4 fractions for primary lung cancer using a stereotactic body frame. Int $J$ Radiat Oncol Biol Phys 2005;63:1427-31. http://dx.doi.org/10.1016/j.ijrobp.2005.05.

[45] Koto M, Takai Y, Ogawa Y, Matsushita H, Takeda K, Takahashi C, et al. A phase II study on stereotactic body radiotherapy for stage I non-small cell lung cancer. Radiother Oncol 2007;85:429-34. http://dx.doi.org/10.1016/j.radonc.2007.10. 017.

[46] Onishi H, Kuriyama K, Komiyama T, Tanaka S, Sano N, Marino K, et al. Clinical outcomes of stereotactic radiotherapy for stage I non-small cell lung cancer using a novel irradiation technique: patient self-controlled breath-hold and beam switching using a combination of linear accelerator and CT scanner. Lung cancer 2004;45:45-55. http://dx.doi.org/10.1016/j.lungcan.2004.01.004.

[47] Shirato H, Shimizu S, Kunieda T, Kitamura K, van Herk M, Kagei K. Physical aspects of a real-time tumor-tracking system for gated radiotherapy. Int J Radiat Oncol Biol Phys 2000;48:1187-95.

[48] Onimaru R, Fujino M, Yamazaki K, Onodera Y, Taguchi H, Katoh N, et al. Steep Dose-Response Relationship for Stage I Non-Small-Cell Lung Cancer Using Hypofractionated High-Dose Irradiation by Real-Time Tumor-Tracking Radiotherapy. Int J Radiat Oncol Biol Phys 2008;70:374-81. http://dx.doi.org/10. 1016/j.ijrobp.2007.06.043.

[49] Mampuya WA, Nakamura M, Matsuo Y, Ueki N, Iizuka Y, Fujimoto T, et al. Interfraction variation in lung tumor position with abdominal compression during stereotactic body radiotherapy. Med Phys 2013;40:91718. http://dx.doi.org/10. 1118/1.4819940.

[50] Bouilhol G, Ayadi M, Rit S, Thengumpallil S, Schaerer J, Vandemeulebroucke J, et al. Is abdominal compression useful in lung stereotactic body radiation therapy? a 4DCT and dosimetric lobe-dependent study. Phys Medica 2013;29:333-40. http://dx.doi.org/10.1016/j.ejmp.2012.04.006.

[51] Caillet V, Booth JT, Keall P. IGRT and motion management during lung SBRT delivery. Phys Medica 2017. http://dx.doi.org/10.1016/j.ejmp.2017.06.006.

[52] Sonke J-J, Rossi MMG, Wolthaus J, van Herk M, Damen E, Belderbos JSA. Frameless stereotactic body radiotherapy for lung cancer using four-dimensional cone beam ct guidance. Int J Radiat Oncol 2009;74:567-74. http://dx.doi.org/10 1016/j.ijrobp.2008.08.004.

[53] Bissonnette JP, Franks KN, Purdie TG, Moseley DJ, Sonke JJ, Jaffray DA, et al. Quantifying interfraction and intrafraction tumor motion in lung stereotactic body radiotherapy using respiration-correlated cone beam computed tomography. Int $\mathrm{J}$ Radiat Oncol Biol Phys 2009;75:688-95. http://dx.doi.org/10.1016/j.ijrobp.2008. 11.066.

[54] Takao S, Miyamoto N, Matsuura T, Onimaru R, Katoh N, Inoue T, et al. Intrafractional baseline shift or drift of lung tumor motion during gated radiation therapy with a real-time tumor-tracking system. Int $\mathrm{J}$ Radiat Oncol 2016;94:172-80. http://dx.doi.org/10.1016/j.ijrobp.2015.09.024.

[55] Hazelaar C, Dahele M, Scheib S, Slotman BJ, Verbakel WFAR. Verifying tumor position during stereotactic body radiation therapy delivery using (limited-arc) cone beam computed tomography imaging. Radiother Oncol 2017;123:355-62. http://dx.doi.org/10.1016/j.radonc.2017.04.022.

[56] Van Herk M, Ploeger L, Sonke J. A novel method for megavoltage scatter correction in cone-beam CT acquired concurrent with rotational irradiation. Radiother Oncol 2011;100:365-9. http://dx.doi.org/10.1016/j.radonc.2011.08.019.

[57] Nakagawa K, Haga A, Shiraishi K, Yamashita H, Igaki H, Terahara A, et al. First clinical cone-beam CT imaging during volumetric modulated arc therapy. Radiother Oncol 2009;90:422-3. http://dx.doi.org/10.1016/j.radonc.2008.11. 009.

58] Li R, Han B, Meng B, Maxim P, Xing L, Koong A. Clinical implementation of intrafraction cone beam computed tomography imaging during lung tumor stereotactic ablative radiation therapy. Int J Radiat Oncol Biol Phys 2013;87(917):23. http://dx.doi.org/10.1016/j.ijrobp.2013.08.015.

[59] Stroom JC, Heijmen BJM. Geometrical uncertainties, radiotherapy planning margins, and the ICRU-62 report. Radiother Oncol 2002;64:75-83. http://dx.doi.org/ 10.1016/S0167-8140(02)00140-8.

[60] Slotman BJ, Lagerwaard FJ, Senan S. 4D imaging for target definition in stereotactic radiotherapy for lung cancer. Acta Oncol 2006;45:966-72. http://dx. doi.org/10.1080/02841860600902817.

[61] Wolthaus JWH, Schneider C, Sonke J-J, van Herk M, Belderbos JS, Rossi MMG, et al. Mid-ventilation CT scan construction from four-dimensional respirationcorrelated CT scans for radiotherapy planning of lung cancer patients. Int J Radiat Oncol Biol Phys 2006;65:1560-71. http://dx.doi.org/10.1016/j.ijrobp.2006.04. 031.

[62] Wolthaus JWH, Sonke J-J, van Herk M, Belderbos JS, Rossi MMG, Lebesque JV. Comparison of different strategies to use four-dimensional computed tomography in treatment planning for lung cancer patients. Int $\mathrm{J}$ Radiat Oncol Biol Phys 2008;70:1229-38. http://dx.doi.org/10.1016/j.ijrobp.2007.11.042.

[63] Baumann P, Nyman J, Hoyer M, Wennberg B, Gagliardi G, Lax I, et al. Outcome in a prospective phase II trial of medically inoperable stage i non - small-cell lung cancer patients treated with stereotactic body radiotherapy. J Clin Oncol 2009;27:3290-6. http://dx.doi.org/10.1200/JCO.2008.21.5681.

[64] Timmerman RD, Galvin JM, Michalski J, Straube WL, Ibbott G, Martin E, et al. Accreditation and quality assurance for Radiation Therapy Oncology Group: multicenter clinical trials using Stereotactic Body Radiation Therapy in lung cancer. Acta Oncol 2006;45:779-86. http://dx.doi.org/10.1080/ 02841860600902213.

[65] van Herk M. Errors and margins in radiotherapy. Semin Radiat Oncol 2004;14:52-64. http://dx.doi.org/10.1053/j.semradonc.2003.10.003.

[66] Schwarz M, Cattaneo GM, Marrazzo L. Geometrical and dosimetrical uncertaintie in hypofractionated radiotherapy of the lung: a review. Phys Medica 2017;36:126-39. http://dx.doi.org/10.1016/j.ejmp.2017.02.011.

[67] Peulen H, Belderbos J, Rossi M, Sonke JJ. Mid-ventilation based PTV margins in Stereotactic Body Radiotherapy (SBRT): a clinical evaluation. Radiother Oncol 2014;110:511-6. http://dx.doi.org/10.1016/j.radonc.2014.01.010.

[68] Lax I. Target dose versus extratarget dose in stereotactic radiosurgery. Acta Onco 1993;32:453-7. http://dx.doi.org/10.3109/02841869309093624.

[69] Hurkmans CW, Cuijpers JP, Lagerwaard FJ, Widder J, van der Heide UA, Schuring $\mathrm{D}$, et al. Recommendations for implementing stereotactic radiotherapy in peripheral stage IA non-small cell lung cancer: report from the Quality Assurance Working Party of the randomised phase III ROSEL study. Radiat Oncol 2009;4:1. http://dx.doi.org/10.1186/1748-717X-4-1.

[70] Videtic GMM, Hu C, Singh AK, Joe Y, Komaki R, Urbanic JJ, et al. NRG Oncology RTOG 0915 (NCCTG N0927): A Randomized Phase II Study Comparing 2 Stereotactic Body Radiation Therapy (SBRT) Schedules for Medically Inoperable Patients with Stage I Peripheral Non-Small Cell Lung Cancer. Int J Radiat Oncol Biol Phys 2015;93:757-64. http://dx.doi.org/10.1016/j.ijrobp.2015.07.2260. NRG.

[71] Lax I, Blomgren H, Larson D, Näslund I. Extracranial stereotactic radiosurgery of localized targets. J Radiosurgery 1998;1:135-48. http://dx.doi.org/10.1023/ B:JORA.0000010898.87146.2e.

[72] Giglioli FR, Strigari L, Ragona R, Borzì GR, Cagni E, Carbonini C, et al. Lung stereotactic ablative body radiotherapy: a large scale multi-institutional planning comparison for interpreting results of multi-institutional studies. Phys Medica 2016. http://dx.doi.org/10.1016/j.ejmp.2016.03.015.

[73] Onishi H, Shirato H, Nagata Y, Hiraoka M, Fujino M, Gomi K, et al. Stereotactic body radiotherapy (SBRT) for operable Stage i non-small-cell lung cancer: can SBRT be comparable to surgery? Int J Radiat Oncol Biol Phys 2011;81:1352-8. http://dx.doi.org/10.1016/j.ijrobp. 2009.07.1751.

[74] Liang X, Penagaricano J, Zheng D, Morrill S, Zhang X, Corry P, et al. Radiobiological impact of dose calculation algorithms on biologically optimized IMRT lung stereotactic body radiation therapy plans. Radiat Oncol 2016;11:10. http://dx.doi.org/10.1186/s13014-015-0578-2.

[75] Ricardi U, Badellino S, Filippi AR. What do radiation oncologists require for future advancements in lung SBRT ? Phys Medica 2016. http://dx.doi.org/10.1016/j. ejmp.2016.11.114.

[76] Knöös T, Wieslander E, Cozzi L, Brink C, Fogliata A, Albers D, et al. Comparison of dose calculation algorithms for treatment planning in external photon beam therapy for clinical situations. Phys Med Biol 2006;51:5785-807. http://dx.doi. org/10.1088/0031-9155/51/22/005.

[77] Liu HH, Keall P, Hendee WR. Dm rather than Dw should be used in Monte Carlo treatment planning. Med Phys 2002;29:922. http://dx.doi.org/10.1118/1. 1473137.

[78] Chetty IJ, Curran B, Cygler JE, DeMarco JJ, Ezzell G, Faddegon B, et al. Report of the AAPM Task Group No. 105: issues associated with clinical implementation of Monte Carlo-based photon and electron external beam treatment planning. Med Phys 2007;34:4818-53. http://dx.doi.org/10.1118/1.2795842.

[79] Fogliata A, Cozzi L. Dose calculation algorithm accuracy for small fields in nonhomogeneous media: the lung SBRT case. Phys Medica 2016. http://dx.doi.org/ 10.1016/j.ejmp.2016.11.104.

[80] Latifi K, Oliver J, Baker R, Dilling TJ, Stevens CW, Kim J, et al. Study of 201 nonsmall cell lung cancer patients given stereotactic ablative radiation therapy shows local control dependence on dose calculation algorithm. Int J Radiat Oncol Biol Phys 2014;88:1108-13. http://dx.doi.org/10.1016/j.ijrobp.2013.12.047.

[81] Chetty IJ, Devpura S, Liu D, Chen D, Li H, Wen N, et al. Correlation of dose computed using different algorithms with local control following stereotactic ablative radiotherapy (SABR)-based treatment of non-small-cell lung cancer. Radiother Oncol 2013;109:498-504. http://dx.doi.org/10.1016/j.radonc.2013. 10.012 .

[82] Xiao Y, Papiez L, Paulus R, Timmerman R, Straube WL, Bosch WR, et al. Dosimetric evaluation of heterogeneity corrections for RTOG 0236: stereotactic body radiotherapy of inoperable stage I-II non-small-cell lung cancer. Int J Radia Oncol Biol Phys 2009;73:1235-42. http://dx.doi.org/10.1016/j.ijrobp.2008.11. 
019.

[83] Kroon PS, Hol S, Essers M. Dosimetric accuracy and clinical quality of Acuros XB and AAA dose calculation algorithm for stereotactic and conventional lung volumetric modulated arc therapy plans. Radiat Oncol 2013;8:149. http://dx.doi.org/ 10.1186/1748-717X-8-149.

[84] Knopf A-C, Stuitzer K, Richter C, Rucinski A, da Silva J, Phillips J, et al. Required transition from research to clinical application: report on the 4D treatment planning workshops 2014 and 2015. Phys Med 2016;32:874-82. http://dx.doi.org/10. 1016/j.ejmp.2016.05.064.

[85] Kadoya N, Nakajima Y, Saito M, Miyabe Y, Kurooka M, Kito S, et al. Multi-institutional validation study of commercially available deformable image registration software for thoracic images. Int J Radiat Oncol Biol Phys 2016;96:422-31. http://dx.doi.org/10.1016/j.ijrobp.2016.05.012.

[86] Brock KK, Mutic S, McNutt TR, Li H, Kessler ML. Use of image registration and fusion algorithms and techniques in radiotherapy: report of the AAPM radiation therapy committee task Group No. 132. Med Phys 2017;44:43-76. http://dx.doi org/10.1002/MP.12256.

[87] Samavati N, Velec M, Brock KK. Effect of deformable registration uncertainty on lung SBRT dose accumulation. Med Phys 2016;43:233-40. http://dx.doi.org/10. $1118 / 1.4938412$

[88] Cai W, Dhou S, Cifter F, Myronakis M, Hurwitz MH, Williams CL, et al. 4D cone beam CT-based dose assessment for SBRT lung cancer treatment. Phys Med Biol 2016;61:554-68. http://dx.doi.org/10.1088/0031-9155/61/2/554.

[89] Chan MKH, Kwong DLW, Law GML, Tam E, Tong A, Lee V, et al. Dosimetric evaluation of four-dimensional dose distributions of CyberKnife and volumetricmodulated arc radiotherapy in stereotactic body lung radiotherapy. J Appl Clin Med Phys 2013;14:4229. doi: 10.1120/jacmp.v14i4.4229.

[90] Scorsetti M, Alongi F, Castiglioni S, Clivio A, Fogliata A, Lobefalo F, et al. Feasibility and early clinical assessment of flattening filter free (FFF) based stereotactic body radiotherapy (SBRT) treatments. Radiat Oncol 2011;6:113. http:// dx.doi.org/10.1186/1748-717X-6-113.

[91] Stambaugh C, Nelms BE, Dilling T, Stevens C, Latifi K, Zhang G, et al. Experimentally studied dynamic dose interplay does not meaningfully affect target dose in VMAT SBRT lung treatments. Med Phys 2013;40:91710. http://dx.doi.org/ $10.1118 / 1.4818255$

[92] Snider JW, Oermann EK, Chen V, Rabin J, Suy S, Yu X, et al. CyberKnife with tumor tracking: an effective treatment for high-risk surgical patients with single peripheral lung metastases. Front Oncol 2012;2:1-5. http://dx.doi.org/10.3389/ fonc. 2012.00063

[93] Jung J, Song SY, Yoon SM, Kwak J, Yoon K, Choi W, et al. Verification of accuracy of cyberknife tumor-tracking radiation therapy using patient-specific lung phantoms. Int J Radiat Oncol Biol Phys 2017;92:745-53. http://dx.doi.org/10.1016/j ijrobp.2015.02.055.

[94] Péguret N, Ozsahin M, Zeverino M, Belmondo B, Durham AD, Lovis A, et al. Apnealike suppression of respiratory motion: first evaluation in radiotherapy. Radiother Oncol 2016;118:220-6. http://dx.doi.org/10.1016/j.radonc.2015.10.011.

[95] Klein EE, Hanley J, Bayouth J, Yin F-F, Simon W, Dresser S, et al. Task Group 142 report: Quality assurance of medical accelerators. Med Phys 2009;36:4197. http:// dx.doi.org/10.1118/1.3190392.

[96] Kim J, Jin JY, Walls N, Nurushev T, Movsas B, Chetty IJ, et al. Image-guided localization accuracy of stereoscopic planar and volumetric imaging methods for stereotactic radiation surgery and stereotactic body radiation therapy: a phantom study. Int J Radiat Oncol Biol Phys 2011;79:1588-96. http://dx.doi.org/10.1016/ j.ijrobp.2010.05.052.

[97] Lutz W, Winston K, Maleki N. A system for stereotactic radiosurgery with a linear accelerator. Int J Radiat Oncol Biol Phys 1988;14:373-81.

[98] Mamalui-hunter M, Li H, Low DA. Linac mechanic QA using a cylindrical phantom.
Phys Med Biol 2008;53:5139-49. http://dx.doi.org/10.1088/0031-9155/53/18/ 019.

[99] Rowshanfarzad P, Sabet M, O'Connor DJ, Greer PB. Isocenter verification for linac based stereotactic radiation therapy: review of principles and techniques. J Appl Clin Med Phys 2011;12:3645.

[100] Followill DS, Evans DR, Cherry C, Molineu A, Fisher G, Hanson WF, et al. Design, development, and implementation of the radiological physics center's pelvis and thorax anthropomorphic quality assurance phantoms. Med Phys 2007;34:2070-6. http://dx.doi.org/10.1118/1.2737158.

[101] Cook MC, Roper J, Elder ES, Schreibmann E. Technical Note: Unified imaging and robotic couch quality assurance. Med Phys 2016;43:5080. http://dx.doi.org/10. 1118/1.4960369.

[102] Hurkmans CW, Van Lieshout M, Schuring D, Van Heumen MJT, Cuijpers JP, Lagerwaard FJ, et al. Quality assurance of 4D-CT scan techniques in multicenter phase III trial of surgery versus stereotactic radiotherapy (radiosurgery or surgery for operable early stage (Stage 1A) non-small-cell lung cancer [ROSEL] study). In J Radiat Oncol Biol Phys 2011;80:918-27. http://dx.doi.org/10.1016/j.ijrobp. 2010.08.017.

[103] Dieterich S, Cavedon C, Chuang CF, Cohen AB, Garrett JA, Lee CL, et al. Report of AAPM TG 135: quality assurance for robotic radiosurgery. Med Phys 2011;38:2914. http://dx.doi.org/10.1118/1.3579139.

[104] Alfonso R, Andreo P, Capote R, Huq MS, Kilby W, Kjäll P, et al. A new formalism for reference dosimetry of small and nonstandard fields. Med Phys 2008;35:5179-86. http://dx.doi.org/10.1118/1.3005481.

[105] Fogliata A, Garcia R, Knöös T, Nicolini G, Clivio A, Vanetti E, et al. Definition of parameters for quality assurance of flattening filter free (FFF) photon beams in radiation therapy. Med Phys 2012;39:6455-64. http://dx.doi.org/10.1118/1. 4754799.

[106] Fogliata A, Fleckenstein J, Schneider F, Pachoud M, Ghandour S, Krauss H, et al Flattening filter free beams from TrueBeam and Versa HD units: evaluation of the parameters for quality assurance. Med Phys 2015;43:205-12. http://dx.doi.org/ 10.1118/1.4938060

[107] Olch AJ, Gerig L, Li H, Mihaylov I, Morgan A. Dosimetric effects caused by couch tops and immobilization devices: report of AAPM Task Group 176. Med Phys 2014;41:61501. http://dx.doi.org/10.1118/1.4876299.

[108] Wang Y, Khan MK, Ting JY, Easterling SB. Surface dose investigation of the flattening filter-free photon beams. Int J Radiat Oncol Biol Phys 2012;83:e281-5. http://dx.doi.org/10.1016/j.ijrobp.2011.12.064.

[109] Kim J, Wen N, Jin J-Y, Walls N, Kim S, Li H, et al. Clinical commissioning and use of the Novalis Tx linear accelerator for SRS and SBRT. J Appl Clin Med Phys 2012;13:3729.

[110] Solberg TD, Medin PM, Ramirez E, Ding C, Foster RD, Yordy J. Commissioning and initial stereotactic ablative radiotherapy experience with Vero. J Appl Clin Med Phys 2014;15:205-25.

[111] McCurdy BMC, McCowan PM. In vivo dosimetry for lung radiotherapy including SBRT. Phys Medica 2017. http://dx.doi.org/10.1016/j.ejmp.2017.05.065.

[112] Kestin L, Grills I, Guckenberger M, Belderbos J, Hope AJ, Werner-Wasik M, et al. Dose-response relationship with clinical outcome for lung stereotactic body radiotherapy (SBRT) delivered via online image guidance. Radiother Oncol 2014;110:499-504. http://dx.doi.org/10.1016/j.radonc.2014.02.002.

[113] Lambrecht M, Melidis C, Sonke J-J, Adebahr S, Boellaard R, Verheij M, et al. Lungtech, a phase II EORTC trial of SBRT for centrally located lung tumours - a clinical physics perspective. Radiat Oncol 2016;11:7. http://dx.doi.org/10.1186/ s13014-015-0567-5.

[114] Menten MJ, Wetscherek A, Fast MF. Physica Medica MRI-guided lung SBRT: present and future developments. Phys Medica 2017. http://dx.doi.org/10.1016/j. ejmp.2017.02.003. 